\title{
LENGUAS EN CONTACTO EN LA SIERRA NORTE DEL PERÚ. UNA PERSPECTIVA COGNITIVA EN LA DIALECTOLOGÍA DEL CASTELLANO
}

\author{
Mg. Emérita Escobar Zapata \\ Profesora del Departamento de Ciencias Humanas de la \\ Universidad Nacional Agraria La Molina \\ escobar@lamolina.edu.pe \\ yhemil@yahoo.es
}

\begin{abstract}
Resumen
En la presente investigación, nuestro propósito central es, a la luz de los supuestos teóricos de la lingüística cognitiva y la pragmática, abordar el estudio de los procesos y fenómenos dialectológicos y sociolingüísticos en el castellano andino de la sierra norte del Perú, específicamente, en los distritos de Luchubamba y Condebamba, provincia de Cajabamba, departamento de Cajamarca. Analizaremos casos como: "antes en mi joventud, saludábamos [de voce] (en voz alta), [ de donde vase] (¿a donde vas?), [cuándo vas a volvere] (cuando vas a volver), asimismo, nos interesa identificar los factores que participan en su producción.
\end{abstract}

Palabra clave: Análisis sociolingüístico, contacto de lenguas, interferencias lingüísticas, bilingüismo, español andino, análisis cognitivo.

\begin{abstract}
In this research, our central purpose is, in the light of the theoretical assumptions of cognitive linguistics and pragmatics, to approach the study of the processes and phenomena from dialectology and sociolinguistics in the Spanish spoken now in the Andean highlands of northern Peru, specifically, Districts and Luchubamba Condebamba, Cajabamba province, Cajamarca department. Analyze cases such as: "earlier in my youth, greeted [de voce] (aloud), [where vase] (Where are you going?), [When you volvere] (when you will return), we are also interested in identifying factors involved in its production.
\end{abstract}

Key words: Sociolinguistic analysis, contact languages, linguistic interference, bilingualism, Spanish Andean cognitive analysis 


\section{Introducción}

En el Perú, desde la perspectiva histórica, el ininterrumpido contacto del español, con el quechua y con los sutratos de otras lenguas ya extintas, mantenido desde hace mas de cuatro siglos ${ }^{1}$, habría ejercido una gran influencia en la configuración del diasistema ${ }^{2}$ del castellano andino, constituido en todo un 'haz' ${ }^{3} \mathrm{de}$ variedades dialectales de los pueblos de la sierra, afectadas con el paso del tiempo, bajo las distintas modalidades de condicionamiento dialectológico y dinámicas sociolingüísticas, producidas en la sierra norte, centro y sur del país, en coherencia y armonía con la heterogeneidad y variopinta realidad pluricultural existente, desde épocas ancestrales.

No siempre los fenómenos de contacto se miden a partir de situaciones bilingues o multilungues; también, en una situación de reducción de las situaciones del bilinguismo, como en el caso concreto de la sierra norte, en la que sólo quedan actualmente dos pueblos que siguen hablando quechua: Chetilla y Porcón, pues, es impresionante la cantidad de rasgos provenientes históricamente del sustrato quechua y culle ${ }^{4}$ en el español; allí, es plausible identificar un alto grado de producción de isoglosas de carácter gramatical y pragmático, que reflejan características susceptibles de ser analizadas, a partir del enfoque pragmático y cognitivo.

Nuestra intención aquí es centrarnos en el análisis de los procesos y fenómenos dialectológicos y sociolingüísticos en la sierra norte: distritos de Luchubamba y
Condebamba, provincia de Cajabamba, departamento de Cajamarca; en un estudio posterior se presentarán los datos de la sierra central y sur del Perú. Este documento constituye nuestro primer acercamiento al estudio de la dialectología del castellano en el Perú, y, por lo tanto, en sucesivos trabajos se irá dando cuenta de nuevos resultados.

A continuación planteamos tres preguntas, que se erigen en el norte de la presente investigación:

1. ¿Por qué resulta estratégico señalar, desde la perspectiva diacrónica ${ }^{5}$, la influencia de las lenguas culle y quechua $^{6}$, una de las dos lenguas mayores en el antiguo Perú, en la configuración y desarrollo del español andino ${ }^{7}$ hablado actualmente en el Perú, es el caso de la sierra norte?

2. ¿Por qué resulta importante, en una situación de contacto de lenguas ${ }^{8} y$ presencia de procesos de variación lingüística, aplicar al estudio un enfoque pragmático cognitivo?

3. ¿Cuáles los factores que condicionan la existencia de procesos y fenómenos asociados a las interferencias lingüísticas en situaciones de coexistencias de lenguas, como el caso que abordamos aquí?

\section{Antecedentes del problema ${ }^{9}$}

Es notorio que, los estudios relacionados con los fenómenos del contacto lingüístico se producen en el seno de toda sociedad donde hay más de una lengua o práctica 
interdialectal, así ha venido mostrando la copiosa documentación que, actualmente, existe de estudiosos, que han sentido una gran atracción por incursionar en esta temática. Quienes ${ }^{10}$, han descrito y explicado el influjo de las lenguas de los andes centrales y meridionales sobre el castellano traído, desde la península ibérica hasta América, señalan la existencia de la producción de todo un 'haz' de interferencias y procesos sociolingüísticos, que se habrían generado como producto de un rico y fluido intercambio con las lenguas amerindias. En países como Méjico, Paraguay, Colombia, Argentina, Bolivia, Ecuador, Perú, entre otros, el léxico hispano se habría visto enriquecido o, en su defecto afectado por los préstamos de las lenguas autóctonas de estos lugares y, los fenómenos de variación dialectal, en los niveles fónico, léxico, morfosintáctico y semántico.

A continuación, veamos lo que afirma De Granda, Germán ${ }^{11}$ : 2001, p. 16:

"[...] es de destacar, [...], la abundancia y solidez de las monografías destinadas, desde diferentes puntos de partida metodológicos, a dar razón con carácter panorámico o en relación con aspectos puntuales, de las implicaciones de toda índole que derivan de la coexistencia e interacción de lenguas ${ }^{12}$ en sus diferentes modalidades. Pero además, y de modo primordial, la publicación, recientísima en el tiempo, de algunas obras teóricas sobre esta misma temática que, por la notable acumulación de datos, la originalidad del tratamiento y análisis de los mismos y la excepcional agudeza y la altura de la elaboración conceptual, [...] los fenómenos lingüísticos a ser abordados a partir de categorías interpretativas renovadas $y$, en cierto sentido al menos, mucho mejor adaptadas a la realidad de los complejos procesos lingüísticos derivados de las situaciones de contacto de códigos comunicativos. [...]"

Efectivamente, tal como se señala en la cita anterior, las investigaciones de índole sociolingüística en estos últimos años se empiezan a percibir con una nueva aureola, con más madurez; crean nuevas metodologías y estrategias, capaces de analizar los distintos condicionamientos en situaciones de contacto de lenguas; asimismo, advierten, por ejemplo, la importancia que representa el hecho de mirar los datos históricos como posibles factores que llevan a tener mediciones distintas, pues sabemos que existen comunidades o zonas donde se ha producido la extinción de lenguas amerindias, desde hace más de trescientos años; otras, donde aún perviven los idiomas indígenas y ejercen una influencia en el castellano.

En la investigación de Escobar, Ana María: 2000: pp. 249-258, en relación al tema de nuestro interés, esto es, el castellano en contacto con las lenguas andinas considera que este tema es ideal para el desarrollo de una investigación de este tipo en el Perú y, por ello, ocupa casi más de la mitad de los capítulos a dar cuenta de procesos morfosintácticos, explica los cambios lingüísticos, pues, incluso, inicia el análisis con la identificación de un conjunto de factores que pueden estar mediando, condicionando los cambios lingüísticos. A todas luces hace una ex- 
haustiva revisión de la literatura relacionada con el tópico, esto se puede inferir al ver las numerosas referencias bibliográficas, asimismo, aborda lo relacionado al fenómeno de las interferencias lingüísticas, sus características, permeabilidad lingüística e innovación restringida; en relación al contacto de lenguas afirma lo siguiente:

"La situación de contacto entre el español y el quechua constituye [...] una fuente muy rica de estudio. La situación ideal de máxima distancia entre las dos lenguas y la estabilidad de la variedad lingüística permiten que mediante su estudio podamos responder una serie de preguntas que preocupan a los estudiosos de las lenguas en contacto, del español, de la adquisición, del cambio lingüístico y de las tendencias universales. Futuros estudios detallados sobre las características lingüísticas y los procesos lingüísticos[...] nos permitirán ver más claramente las características de las interferencias lingüísticas, su rol en el cambiodelalenguay, consecuentemente, el rol de la permeabilidad lingüística en una situación de contacto. [...] entender mejor la relación entre la lengua y la sociedad que, en nuestro caso, define la identidad nacional peruana."

Con respecto al enfoque teórico de la lingüística cognitiva podemos comentar que quienes han abordado el estudio de este tipo de fenómenos, lo han hecho mayormente, desde la teoría del cambio, desde la dialectología ${ }^{13}$ así como al fenómeno de contacto de lenguas ${ }^{14}$, aquí interesa sobre todo enfocar el estudio desde los alcances de la lingüística cognitiva y pragmática ${ }^{15}$, en este último caso los investigadores anotan que interesa analizar la lengua en cuanto al uso en la sociedad, en situaciones concretas, en los actos comunicativos y, qué principios se cumplen entre los interlocutores. A continuación presentamos una breve información con respecto a la lingüística cognitiva.

La lingüística cognitiva surge al amparo de la disciplina científica conocida, de forma genérica, como ciencia cognitiva. Ésta es una disciplina relativamente reciente, de no mucho más de 25 ańos. Se ha ocupado de comprender la naturaleza de diversas operaciones mentales relacionadas con el razonamiento, la memoria, la organización del conocimiento y el procesamiento y la producción lingüística, entre otras. En la línea de estas investigaciones la lingüística cognitiva se ha ocupado especialmente de los problemas de la categorización conceptual (teoría de los prototipos y de las categorías de nivel básico), de los modos de organizar y almacenar conocimiento dentro de una concepción enciclopédica de la semántica (Haiman, 1980; Langacker, 1987), de la conexión entre la conceptualización, el razonamiento y las categorías conceptuales enraizadas en nuestra experiencia sensorial y motora respecto al entorno $[\ldots]$

Para Langacker (1987, 1990, 1991), un sistema lingüístico consta, primero, de estructuras semánticas, fonológicas y simbólicas que se manifiestan como expresiones reales, segundo, de abstracciones o esquematizaciones de dichas estructuras y, tercero, de relaciones de categorización entre estructuras posibles. Evidentemente, los hablantes escogen expresarse de forma más o menos explícita como parte de su juego estratégico y de los requisitos contextuales. Por ejemplo, en un contexto en el que hablante y oyente son amigos, o regularmente se 
expresan un afecto especial, pueden ser capaces de agregar un elemento de la lengua que sirve o indica 'afecto', 'aprecio'. Hay, no cabe duda, un conjunto finito de presupuestos de carácter pragmático que los interlocutores aplican en la instanciación de sus eventos de habla.

No cabe duda que la lingüística cognitiva es una visión susceptible de ser aplicada a conjunto de datos lingüísticos, para explicar diversas construcciones y usos del lenguaje de acuerdo con los parámetros explicativos de la teoría de los modelos cognitivos idealizados. [...] ( $c f$. Francisco José Ruiz de Mendoza Ibáñez: 2001).

\section{Las interferencias lingüísticas en la sierra norte ${ }^{16}$}

En este acápite se presentan las interferencias registradas en la variedad del castellano norteño de Cajabamba, relacionadas con los aspectos gramaticales y pragmáticos. Aquí nos han llamado la atención formas como: Chorobamba, guapenque', cushpenga que se escuchan en las emisiones de los castellano hablantes de los distritos de Condebamba y Luchubamba, provincia de Cajambamba-Cajamarca, que a todas luces provienen de las lenguas quechua y culle respectivamente.

\subsection{Aspecto fonológico}

Para la transcripción de las palabras en castellano andino se utilizará el sistema ortográfico práctico y se utilizarán corchetes en tanto, estos dan la idea de la pronunciación. Los datos corresponden al castellano hablado en la provincia de
Cajabamba, distritos de Condebamba (caseríos de Luchubamba y San Isidro). A continuación presentamos las variaciones vocálicas:

\subsubsection{Cambio de vocal ${ }^{17}$.}

A continuación se presentan casos que ilustran el proceso de alzamiento vocálico, es decir, la ocurrencia de vocales altas /i/, /u/, que devienen de las medias /e/, /o/; asimismo, se registra el proceso inverso, esto es, los sonidos /i/, /u/ se realizan como /e/, /o/. Finalmente, los castellanohablantes de la zona rural de Cajabamba pronuncian como [e], la vocal baja /a/. [tardi... ] 'tarde'; [ollocos] 'ollucos'; [duindi] 'duende'; [il alcaldi] 'el alcalde'; [i lino aquí cultivamos...] 'aqui cultivamos el heno...'; [joventud] 'juventud'; [bonitu] 'bonito'; [le decemos] 'le decimos'; [hamos utilizado] 'hemos utilizado'; [que se vaye]; [vayemos al pueblo] 'vayamos al pueblo'. A todas luces, se advierte una vacilación en la pronunciación de las vocales $y$, naturalmente, lo más plausible, en este caso, es evaluar en hablantes bilingües o andino hablantes que tienen el quechua como lengua materna o donde se ha hablado históricamente este idioma y aún pervive el sustrato. En Quesada, Félix ${ }^{18}$ : 2006: 55-57, voces del quechua norteño de Cajamarca a nivel fonético reproducidas como: [aré:], [tšoqre:], [tšawpI], [wasI] provenientes de laril, lčuqril, /čawpil y / wasi/, respectivamente. A nivel cognitivo los hablantes tendrían una mayor fijación de los esquemas vocálicos, propios de la lengua andina, de modo pues que resulta natural la presencia de interferencias linguísticas de este tipo.

(1) [...que se vaye] '...que se vaya' 
(2) [vayemos al pueblo] 'vayamos al pueblo’

\subsubsection{Inserción de la vocal lel.}

Un segundo caso registrado entre los adultos que habitan en la zona rural, en las zonas ya mencionadas líneas arriba es la inserción de la vocal/e/ en final de palabra, tal como ilustramos con los datos que siguen: [apretare] 'apretar', [saludare] 'saludar', [obedecere] 'obedecer', [... me quería matare... ] 'me quería matar...', [Eso era nostro decire... I'a decir nuestro', [tejere] 'tejer'; [antes en mi joventud saludábamos de voce ] 'antiguamente, en mi juventud saludábamos en voz alta'; [ ... donde vase ] 'donde vas'. Estos y muchos casos más que registraremos en un trabajo posterior más completo, indican el uso categórico de la vocal media /e/ en final de palabra. En el esquema mental de estos pobladores, la vibrante simple en posición final de palabra se pronuncia como /re/; en el quechua el segmento $/ \mathrm{r} /$ ocurre en posición inicial y posición de coda, esto es, siguiendo a una consonante, y no en final de palabra. En consecuencia, el patrón que aplican en esta posición es de reacomodación agregando una vocal para que el vocablo no termine en vibrante. No obstante, los dos últimos casos muestran el mismo cambio pero cuando se acaba en otra consonante, en sibilante /s/.

\subsubsection{Inserción consonántica.}

A continuación presentamos algunos ejemplos que muestran la tendencia a agregar la yod /y/ delante de la vocal alta /i/. Este recurso es aplicado y obser- vado en muchas otras lenguas naturales. [ máyis] 'maiz'; [yi quería] 'y queria'; [... me cáyi] 'me caí, [a veces con los peyones nos dejaba I 'a veces nos dejaba con los peones'

\subsubsection{Reducción de las secuencias vocálicas.}

En los dialectos del castellano andino, y, en este caso, en el de la sierra norteña también encontramos como parte de los rasgos de motosidad ${ }^{19}$, este que consiste en la reducción vocálica. Así: [nosto] - [nostro] 'nuestro'; [pue] - [pe] 'pues'y [apriendan] 'aprendan'. Evidentemente, que este caso es parte de un solo proceso de los cambios o procesos vocálicos en este dialecto y en el diasistema del castellano regional andino.

\subsubsection{Elisión consonántica ${ }^{20}$.}

Otros casos que también llaman la atención, aunque en menor medida es la caída, principalmente, de la consonante oclusiva dental sonora en posición intervocálica y en posición inicial de palabra. Veamos los siguientes ejemplos: [parao] 'parado'; [onte] [onde]; 'dónde...;[lao] 'lado'; [tronchau] 'tronchado'; [olvidau] 'olvidado';[eduacao] 'educado'; [acercao] 'acercado'.

Igualmente, observamos la caída de la oclusiva bilabial sonora /b/ detrás de nasal bilabial: [tamien tenemos...] 'tenemos también...'; finalmente, casos como [entonce... ] 'entonces...' y [pe] 'pues'. ilustran la desaparición de la consonante final. Todos estos cambios están asociados a la articulación del léxico en una segunda lengua, como es caso del caste- 
llano andino, pues se trata de hablantes que no tienen un manejo competente de este idioma.

\subsection{Aspecto morfosintáctico}

Los datos que presentamos a continuación pertenecen a los hablantes de algunos caseríos de Condebamba y Luchubamba, (Cajabamba); las emisiones han sido tomadas directamente de situaciones de conversaciones. Hemos clasificado los datos, tomando en cuenta la mayor a menor producción de los fenómenos de esta naturaleza.: 1) Uso variable de la estructura sintáctica; 2) El doble posesivo; 3) Falsa pronominalización o uso de relativos; 4) Falta de concordancia; 5) Uso de artículo delante de una cláusula u oración y finalmente, 6) Empleo de doble objeto directo. Periféricamente ${ }^{21}$, también se ha observado la omisión de preposiciones. A diferencia de las variaciones o cambios estudiados a nivel fonológico, los fenómenos asociados al componente morfosintáctico más parecieran ser signos que reconstruyen el conocimiento cultural y la intención de los hablantes. En la medida que estos segmentos que estamos usando para la ejemplificación han sido parte de producciones mayores, esto es, en el proceso de la comunicación. En efecto, aquí corresponde mirarlos con una perspectiva en la que se visualice la interacción entre lengua y mundo; entre lengua y cultura; entre lengua y experiencia de los hablantes en su entorno A continuación, se abordará cada uno de los cambios mencionados:

\subsubsection{Uso variable de la estructura sin- táctica}

(3) Y [ø] toda manera que ya no es el estudio como antes era

(4) A la gente acostumbramos, a los cadáveres acostumbramos poner encima coca, licor, cigarro; a la tierra acostumbramos poner flores.

(5) [...] [todo lo que ella decía, la gente todo contenta

(6) Bien rebelde, que toda la gente nada, nada, le contestaba ello

(7) Las cruces, es nomás, que yo he conocido

(8) [...]A barretear nuestras chacras se dedican los hombres.

(9) [...] bastante, yo me iba a verle ${ }^{22}$.

Las estructuras de los componentes sintácticos en las construcciones oracionales de (3) a (6) presentan, a todas luces, una organización propia del quechua. Los casos (7) y (8) más bien muestran seguir un orden OSV OVS; finalmente, en (8) se presenta como SVO. Esta heterogeneidad develaría un rasgo idiosincrásico que estos pobladores de los distritos de Luchubamba y Condebamba. Reflejan el uso de la fluctuación de dos sistemas en la estructuración y construcción sintáctica. Principalmente, las formas (5) - (8) más se asemejan a una variedad criolla ${ }^{23}$. Véase a continuación lo que señala el maestro de la andinística Rodolfo Cerrón Palomino: (2003: 26-27)

"Hay variedades lingüísticas en el país, especialmente en la región andina, que a simple vista podrían ser -y de hecho lo son-consideradas como dialectos del español peruano. Sin embargo, miradas con más detenimiento, ellas parecen más bien 
ser formas que reúnen características de verdaderas variedades criollas o cuasi criollas. [...] el léxico de dichas hablas provienen del español, [...], su sintaxis es, por el contrario francamente quechua. [...] tienen su propia gramática, su propia organización.

\subsubsection{Uso del doble posesivo}

(10) De su tía sus dos gallinas vamos matar

(11) De su vecino su burro

(12) De los campesinos su chagra.

(13) Del alcaldi su tininti se morió.

(14) Ese hay por nuestra tierra de nosotros

(15) $\mathrm{Si}$ acostumbras en tu chacra de ti llevar pa comer

En estos casos de (10) a (14) se puede afirmar que en el castellano de Cajamarca (Cajabamba) también ocurre, al igual que muchos de los dialectos de la zona andina, la marcación del posesivo basado en el principio de la dualidad que consiste en explicitar tanto el elemento de posesión en posición pronominal así como en la pronominal. Esta es una de las características del quechua o del aimara, esto es, tienen esta doble marcación, sin embargo, la razón por la cual echan mano de esta modalidad estaría relacionada con la intención de los hablantes en el momento de la comunicación, ellos tienen un conocimiento que trasciende al aspecto gramatical y este se refleja en el uso de sus constituyentes. Son esquemas cognitivos. Veamos los ejemplos a continuación:

\subsubsection{Falsa pronominalización - Rela-}

\section{tivización}

Ejemplos de la producción de construcciones con seudo pronominalización o una relativización son los presentamos a continuación:

(16a) Que te conocía yo

(16b) Yo conocía 'X'

(17a) Para el trabajo que ti utilizamos

(17b) [...]Utilizamos para el trabajo ' $\mathrm{X}$ '

(18a) Lo que me trataba así

(19b) Me trataba así.

(19a) [...] Y allí he conocido yo...

(19b) [...] Y allí he conocido

(20a) Que he conocido yo, [...]

(20b) Yo he conocido, [...]

Al cotejar los casos (16)- (19) con sus respectivas formas que se han reconstruido como las correctas nos percatamos de un proceso morfosintáctico de relativización. Entonces, ellos, al parecer, agregan el relativo seguido o precedido de un pronominal. En el caso de (5) más parece el caso de un pronominal enfático.

\subsubsection{Falta de concordancia en las construcciones}

En primer término, habría de señalar aquí que, indudablemente, es la falta de manejo de la gramática del castellano, uno de los factores que condiciona la producción de este tipo de interferencia lingüística. Las variables de género, número en la lengua quechua no tienen el mismo comportamiento que en el castellano y por, lo tanto, ellos tienen esquemas relacionados con estas categorías que posiblemente están muy acentuadas y las transfieren fácilmente en el habla hispana de esta región y más aún, en el área rural. 
En lo que sigue se presenta una relación de ejemplos que ilustran el aspecto tratado, líneas arriba:

(21) Eso, la que es la costumbre

(22) La comunidad de Cushuro se creó porque un señor lo descubrió.

(23) $\mathbf{L o}^{25}$ mando a su hermana que se vaye

(24) Mi madre falleció. Yo lo quería a mi madre.

(25) Que más antes usaban nosotros

(26) Que ellos (los profesores) me lo enseñen

(27) A mi madre, a mi tía, los he querido mucho, mucho...

\subsubsection{Uso del determinante delante de una cláusula u oración}

Asimismo, llama la atención que encontremos casos con el uso del artículo delante de una cláusula, y, esto, tomando en cuenta que en su idioma materno no utilizan artículo. ¿Es acaso, que estaría también asociado al hecho pragmático, de estar expresando un hecho definido o no definido, algo conocido o no conocido y, quizá porque en la lengua quechua, tienden a usar elementos discursivos para precisar o dar cuenta de la certeza, evidencia o énfasis de sus expresiones. Buscan reajustar las construcciones a sus patrones cognitivos propios de la lengua nativa. En los que sigue se anotan algunos ejemplos que ilustran la afirmación mencionada antes.

(28) "hablábamos el lo que los patrones...."

(29) "eso... lo que la costumbre es"

\subsubsection{Doble objeto directo o doble acu-}

\section{sativo}

Asimismo, al igual que el doble posesivo, se advierte la presencia de construcciones portando doble constituyente con función de objeto directo. En lo que sigue se presentan tres casos:

(30) "mi papá lo criaba mis pollitos..."

(31) "todo los cumuneros lo iligiron al alcalde

(32) Al muchacho, los brazos, lo sobábamos.

\subsubsection{Omisión de la preposición}

Finalmente, hemos registrado algunos escasos ejemplos que ilustran la omisión de preposiciones. Tomemos en cuenta que el quechua es una lengua que carece de este elemento, pues, siendo una lengua aglutinante los elementos que sirven para establecer, específicamente, las relaciones se agregan detrás de los núcleos nominales o adjetivales. Ejemplos de este proceso de ausencia preposicional son los siguientes:

(33) Hace daño [ø] la chacra;

(34) Y [ø] toda manera que ya no es el estudio como antes era;

(35) [ø] veces comemos charqui.

\subsubsection{Un Caso entre pobladores de dos caseríos}

Los datos que presentamos a continuación pertenecen a los hablantes del valle interandino de Condebamba (Cajamarca), donde según refieren los pobladores de los caseríos de la provincia de San $\operatorname{Marcos}^{26}$, el habla es distinta y, muchas veces, no se entienden. 
(36a) "Doña Cirila, me mando mi tío que le preste un burro para llevar maiz, présteme su burro para llevar maiz, me mando mi tía gloria"

(36b) "No hay, me dijo, por eso, me volví ya" (37a) "Ya pue doña Cirila minguimi su burro para pasar a la carretera, ya pue le dice lueguito le devuelvo porque caishita ${ }^{27}$ llora, la bebita lo voy a pasar el río en burro; agrega, tía me minga también su pailita.

(37b) ”Cómo es tu paila?” ¡la perolaza será, para sancochar la chochoca ${ }^{28}$ !

(37c) _ ah, ya. "Tía me minga también la perolaza".

La palabra/mingimi/, proviene de la raíz quechua $/ \mathrm{minka} /$ = 'trabajo colectivo, en beneficio de la comunidad o de los amigos' + el sufijo del español /-mi/ que proviene del enclítico castellano: / me/. Esta forma /minguimi/ alterna con la frase castellana /me presta/ o / présteme/, esto generalmente, se registra principalmente en las mujeres antes que en los hombres, muchas de ellas sin estudios o con primaria incompleta, dedicadas a labores en el sector rural, (labor en la chacra, con los animales y como ama de casa). Existe una alternancia en el uso de la voz 'paila' en su forma diminutiva/pailita/, rasgo propio de la zona andina, con la voz 'perolaza' para referirse a un tipo de 'vasija de cocina', 'olla'. Finalmente, en el caso de /cashita/ / caishita/ / caisita/ provienen de la voz culle: caisa 'niño que generalmente es sensible o fácil de llorar. 'Dícese a un niño engreido, mimado'. Pragmáticamente, utilizan con precisión este término para referirse a una situación y con la experiencia que se tiene de estar frente a un niño que fácilmente puede llorar o que requiere cuidado.

\subsection{Aspecto léxico-semántico}

(38) [estate] quédate

(39) [quedito] quieto

(40) [barrica] 'depósito de vasija utilizado para el vino; especie de tonel para reserva de líquidos`

(41) [me demorao una nadita] me he demorado poco

(42) [el quitaluto...] costumbre de dejar de llevar luto.

\subsection{Prestamos léxicos}

(43) [chikllu] 'selección'

(44) [cushal] voz culle: 'Sopa que se sirve en el desayuno a base de trigo tostado y triturado'

(45) [ashuturarse voz culle: 'ponerse en cuclillas'

(46) [pirca, pircar] 'piedras, muro; acción de colocar las pircas para hacer el muro'

(47) [puya] [pulla] 'puñal'

(48) [rancha de papa] 'polilla'

(49) [taksha] 'ritual del lavado de ropa del difunto al día siguiente'

(50) [minga, minka, migas, minguimi] 'trabajo comunitario'

(51) [caminar por las jalcas] 'caminar por las alturas

(52) [lliclla] 'manta'

(53) [urpu] 'cantaro'

(54) [puchka] 'rueca para hilar'

(55) [caishas huachitos] 'niños sin padre ni madre'

\subsection{Aspectos Pragmáticos-Cognitivos Texto No. $1^{29}$.}

"Para ir a trabajar en la chacra llevamos el arado, la garrucha, la punta, la orquilla, el yugo, las coyundas, para que tiren los bueyes y otras cosas, que "cati", nosotros usamos el arado y la garrucha, 
que "cati", pa llevar la carga; también flete necesita el costal, la cincha, para apretare, y nos vamos a la ciudad a vender nuestros productos [...]"

\section{Texto No. $2^{30}$}

"Antes había el resfrío, la gripe, la tosferina y las epidemias, que eran por ejemplo. Nos curábamos con hierba santa, con el agua [...] , nos lavábamos y calmaba un poco de fiebre, que "cati", con la hierba santa estrujada, la cerraja, la verbena también que cati uno se echaba en la vejiga y ahora lo llaman depositario, eso era lo que utilizábamos más antes porque no habían doctores, no había medicina, no había postas médicas a donde correr. Con eso nos curábamos y así nos aliviábamos, calmaba los dolores que teníamos"

\section{Texto No. $3^{31}$}

"En cierta ocasión esperábamos con nuestros compañeros a nuestro profesor, quien solía venir minutos después de todos nosotros, $y$, al verlo aparecer me apresuré a decir, en forma totalmente inesperada para ellos, aunque para mí no: “cati”, allí viene el profesor" _ Yo quise decir, miren allí viene el profesor. ¿Pero "cati", me dijo uno de mis compañeros en un tono despectivo. -¿Qué significa cati, ah?- tú eres indígena."

No cabe duda que en esta variedad de la sierra norteńa, los hablantes de las localidades de Luchubamba y Condebamba, en la zona rural, usan expresiones como "cati", que acuerdo a sus esquemas cognitivos sirven para llamar la atención sobre algo de lo que están hablando y de pronto, quieren explicar algo, recordar, llamar la atención, o a manera de una función conativa en la comunicación interpersonal, surge el uso pragmático de la expresión: “cati". Veamos en la tabla No.1, algunas de las emisiones con este vocablo:

\begin{tabular}{|ll|}
\hline - & [que cati ${ }^{32}$ pa llevar ... ] \\
\hline - & Que cati nosotros usamos el arado. \\
\hline - & Cati, para llevar la carga. \\
- & Cati allí viene el profesor \\
\hline
\end{tabular}

\section{Tabla No. 1. Uso discursivo de la expresión} "cati"

Igualmente, pueden diferenciar a los interlocutores $y$, cambian, a veces, de registro, haciendo uso de palabras que muestran afecto, o trato especial, o como parte de la costumbre andina de utilizar el diminutivo en su habla. Aquí el sufijo <-cho> está unido a las raíces del castellano.

\begin{tabular}{|l|}
\hline - [holacho] 'con afecto' \\
\hline $\begin{array}{l}\text { - [ia dónde vas cho?] '¿A dónde vas?' tono } \\
\text { afectivo' }\end{array}$ \\
\hline - $[$ pacacho] 'por acasito' \\
\hline - [cuyachos] 'cuycitos' \\
\hline $\begin{array}{l}\text { - [hay que churgiarlo al chicacho } \\
\text { bañarlos }{ }^{34} \text { a los chicos' }\end{array}$ \\
\hline
\end{tabular}

Tabla No. 2. Raíces castellanas más un sufijo en quechua

\section{Factores que generan las inter- ferencias lingüísticas}

- El castellano andino de la zona, 
muestra ser reflejo del desarrollo histórico de esquemas ya establecidos en el proceso de aprendizaje del español como segunda lengua, a la llegada de los españoles, patrones en los que se advierte una fluctuación a nivel cognitivo de dos lenguas que tienen una tipología distinta, en tanto, desde el punto genético, devienen de un origen distinto. ¿Cuáles eran los patrones o tipología adquirida a nivel cognitivo de la lengua materna de los andinohablantes a la llegada de los españoles?. Relacionada, naturalmente, con los niveles de la gramática, $y$, con respecto a aspectos pragmático-discursivos. Toda esta experiencia ya fijada en territorio andino habría servido de base para la adquisición del español, e, indubitablemente, factores sicológicos, como los relacionados con el nivel de autoestima, discriminación de los grupos, así como cierta mofa a sus costumbres también podrían haber condicionado a través de los siglos y hasta este periodo contemporáneo la presencia de variedades o dialectos del castellano andino con las particularidades que hemos descrito, líneas arriba.

- La existencia en nuestro territorio de una diversidad de variedades de habla castellana, tanto a nivel local como regional, de un modo general, es el resultado del proceso dinámico de castellanización que, aunque empezara, hace ya más de cuatro siglos, se ha ido afianzando, expandiendo significativamente. Esto lleva a la necesidad de identificar una población variopinta, dentro de la cual se van a registrar múltiples interrelaciones y contactos. Todo esto es consecuencia de los movimientos migratorios.

- El nivel de educación, el nivel de autoestima en el grupo de referencia, estatus social y económico. El hecho, por ejemplo, de ser pobladores de la zona rural en oposición a quienes viven en zona urbana.

- Si Chomsky, Noam hablaba de mecanismos universales para el desarrollo y adquisición de cualquier lengua natural, y, que la competencia lingüística se lograría alrededor de los cuatro años; o de la edad crítica $^{35}$ para el aprendizaje de una lengua, aproximadamente a los nueve años. Nos preguntamos aquí lo siguiente: ¿Qué ocurre en la mente de los hablantes cuando están recién adquiriendo los hábitos lingüísticos en una determinada comunidad donde ya habían desarrollado otros hábitos articulatorios para una lengua ' $\mathrm{X}$ '? Este es el caso de muchos de los pueblos andinos, en los que no siempre el quechua fue la primera lengua aprendida, antes de la llegada de los españoles? Por ejemplo, en Cajamarca se sabe, por la documentación histórica, de la presencia del Culle, como lengua del lugar y que en algún momento habría sido desplaza por esta lengua mayor. De modo que al llegar la lengua peninsular y difundirse por el territorio, muchos de los hablantes ya habían desarrollado cognitivamente, patro- 
nes propios de la coexistencia del quechua con otras lenguas, sino con los sustratos. Indubitablemente, serán los factores ${ }^{36}$ extralingüísticos ${ }^{37}$ de naturaleza sicológica, sociocultural, política, socioeconómica experimentados por estos grupos usuarios hoy en día del castellano andino. Uno bastante arraigado, a todas luces, es el sentir que sus lenguas originarias han sido desplazadas por el castellano. A ello, se va a agregar, el contacto que estos pueblos tienen con hablantes o usuarios de la variedad hispana, aceptada como la estándar, pues siendo del sector rural, en muchos casos, no salen fácilmente de sus localidades.

\section{Conclusiones}

1. De lo dicho anteriormente se deduce que el castellano andino hablado en la provincia de Cajabamba, indubitablemente, es un subsistema del diasistema correspondiente al castellano regional andino.

2. En la dialectología y estudios de contacto de lenguas, es necesario aplicar la visión cognitiva, en tanto, no sólo esclarece y explica la presencia de variaciones desde el lenguaje, o de acuerdo a la gramática, sino que trasciende este módulo y lo asocia a otros saberes que aplican o incluyen los hablantes al producir sus enunciados o en el proceso de la comunicación. Esto es, los saberes del mundo extralingüístico.

3. Al parecer, está claro que existe una clasificación de rasgos de base asociado a los distintos niveles que es propia de comunidades bilingües o de aquellas, como las que hemos estudiado que fijan históricamente, patrones que van a ser transferidos en la producción lingüística del castellano, o su segunda lengua, según el caso.

4. Tanto los resultados de estudios dialectológicos, sociolingüísticos, esto es, de contactos lingüísticos en el Perú, como en los otros países andinos se deben sistematizar a la luz de la comprensión de nuevos enfoques que explican los fenómenos y los factores que condicionan los registros $\mathrm{u}$ ocurrencias en la heterogeneidad de hablas.

5. Entre las comunidades castellanohablantes de Luchubamba y Condebamba, Cajamarca se refleja el uso de sustrato léxico proveniente del idioma culle así como préstamos del quechua que le imprimen rasgos idiosincrásicos a esta variedad, y, en la que los hablantes de la zona rural muestran un manejo incompleto de la lengua oficial. Ocurre una transferencia de los esquemas propios del quechua en las construcciones morfosintácticas, esto es, órdenes no propios del castellano.

6. El quechua y el culle son las lenguas que han dejado allí su impronta, lo que se manifiesta claramente en el léxico ([taksha]). Voz quechua: 'ritual del lavado de ropa de los difuntos al día siguiente'; ([ashuturarse]) voz culle 
'ponerse en cuclillas'.

\section{Notas}

1 “[...] a la llegada de los espańoles, la situación lingüística que presentaba el imperio de los incas era de un verdadero mosaico idiomático. No sólo coexistían en él diversas lenguas, algunas con mayor difusión, sino también muchas de ellas mostraban, unas más que otras distintos grados de diversificación interna" ( $c f$. Gramática o Arte de la lengua general de los Indios de los Reynos del Perú de Domingo de Santo Tomás: 1995).

2 El castellano del mundo lo hablan más de trescientos millones, de distintas maneras, de un modo particular, de modo que son diferentes variedades lingüísticas, que se distinguen por la pronunciación, es decir, diferentes sonidos de los hablantes así como por la entonación, asimismo, por las gramáticas particulares en sus construcciones morfosintácticas y léxico-semánticas.

3 "Una lengua no es, pues, como se cree, un sistema completamente homogéneo; por el contrario, es lo que podríamos llamar, empleando la ya clásica terminología de Weinreich (1968:307), un diasistema, es decir, un sistema de sistemas (diferenciados)". (cf. Cerrón Palomino: 2003: p.: 24).

4 En otros casos encontramos evidencias de sustrato proveniente de la lengua Culle que se habló no sólo en Huamachuco [Santiago de Chuco y Pallasca], sino también en Cajamarca, en los valles de Condebamba, río Crisnejas, San Pablo, incluso antes de la difusión de la lengua quechua. ( $c f$. Fernando Silva Santistes- ban: 1982 citado por Pantoja Alcántara, Isabel del Rocío: 2000).

5 Esta lengua y el aimara definitivamente han transferido gran parte de sus esquemas o tipología en situaciones de bilinguismo.

6 Vigente aún en la zona andina aunque de un modo heterogéneo.

7 En cuanto a haber desarrollado un sistema propio, en este caso, en la zona rural, tomando como base las huellas del quechua y otras lenguas menores.

8 GUERRA, Eliana. 2006. Reseña de "Diagnóstico Sociolingüístico de Cumaribo, Zona de Contacto Indígena-Colono, Vichada" de Héctor Ramírez Cruz. Boletín de Lingüística, Julio-diciembre. Año/vol. XVIII, número 026. Universidad Central de Venezuela. Caracas, Venezuela. pp. 190-200.

9 Dividimos en dos categorías este rubro: 1) Asociados al trabajo de investigación que presentamos, esto es, contacto de lenguas y; 2) Relacionados con el enfoque teórico a utilizar en este documento, esto es, el enfoque cognitivo.

10 Cerrón Palomino: 2003. Castellano Andino. Aspectos sociolingüísticos, pedagógicos y gramaticales es uno de los documentos a tomar en cuenta en este estudio por los valiosos aportes relacionados con el tema, objeto de nuestro estudio.

11 En su artículo titulado: El Influjo de las lenguas Indoamericanas sobre el Español. Un modelo Interpretativo socio histórico de variantes areales de contacto lingüistico, en Estudios de Lingüística Andina. PUCP. Lima, Perú.

12 Montes, José Joaquín: 1986: pp. 335340, "El influjo indígena en el español de Colombia. Caracterización Sumaria", en Revista de Filología, Románica (Ma- 
drid), citado en De Granda, Germán: 2001. pp. 9-35.

13 "Desde el punto de vista teórico, dialectología es el estudio de la variación diatópica y diastrática de la lengua (en los varios "estados" de lengua, y estilos), y no dispone de un método propio y específico para recoger estudiar materiales. ( $c f$. Gimeno Menéndez, Francisco:1990: pp. 16 y 170$)$.

14 Hoy en día este fenómeno es abordado a la luz de nuevas corrientes de pensamientos que echan por tierra preceptos que se basan sólo en criterios internos. ( $c f$. José Joaquín Montes: "El influjo indígena en el español de Colombia. Caracterización sumaria” en Revista de Filología Románica (Madrid). 1986: pp. 335-340.

15 Cf. Victoria Escandell: (1996) 2006.

16 Los datos a utilizar en el análisis sincrónico (para la sierra norte) son el resultado del trabajo de campo llevado a cabo en Cajamarca, en conversación directa con informantes del sexo femenino ( 45 a 65 años) de las provincias de Condebamba y Cajabamba, en el mes de marzo del año 2000.

17 Se registró un caso redondeamiento aunque conservando la misma altura. [barrota] 'barreta'.

18 Quechua de Cajamarca. Fonología. Morfología. Sintaxis. Editorial Mántaro, 2006.

19 Cerrón Palomino: 2003: pp. 94-95 se refiere a la motosidad relacionada con los distintos niveles de la gramática. Uno de ellos es el nivel fonológico.

20 Apócope de sílaba. [ta ] 'está; [ [tan todos] 'están todos'; [paque] 'para que'; [difente] 'diferente'.

21 No se han producido muchos casos o no tenemos suficientes ejemplos.
22 8b En el castellano estándar sería equivalente a: Yo iba a verle frecuentemente.

23 También es el nombre del fruto que es de color verde cushuro. Como medio verde, ese fruto con la papa se come y se prepara.

24 Se podría hablar, específicamente, de una neutralización del uso de 'lo'.

25 Los datos que transcribimos, en parte corresponden a cuatro de nuestros infomantes, con quienes se estableció una conversación directa.

26 "Y la caisha Adán, sin taita! ;" (cf. Ciro Alegría).

27 Es el maíz que se sancocha, lo hacen secar en el sol, lo muelen y lo cocinan para hacer sopa.

28 En relación al trabajo de la chacra.

29 Relacionado con las enfermedades y curación.

30 Texto tomado del artículo: El dialecto, la voz de los pueblos por excelencia de Jacinto Luis Cerna Cabrera: 2005. Chetilla, Cajamarca.

31 Uso pragmático que usan los pobladores de la zona rural, esto es, entre campesinos, durante el discurso, para llamar la atención de algo que quieren informar mientras se está realizando simultáneamente otra acción o actividad.

32 Con gran sensibilidad por la enfermedad del chico.

33 Churgar = bañar con plantas medicinales.

34 Kenji Hakuta: (1997) 1999: A Critical Period for Second Language Acquisition?. A Status Review. Stanford University.

35 "El grado de conocimiento de la segunda lengua por parte de los hablantes y los factores socioculturales que rodean la comunidad desempeñarán un papel fun- 
damental en la influencia lingüística que una lengua puede ejercer sobre otra" $c f$. Thomason: 2001: citado por Palacios Alcaine, Azucena: 1997.

36 Tanto los niños como los jóvenes o los adultos perciben y desarrollan cognitivamente interferencias linguísticas condicionados por factores de origen múltiple.

\section{Referencias Bibliográficas}

CALVO PÉREZ, J. (ED.). Teoría y práctica del contacto: El español de América en el candelero. Madrid, Vervuert Iberoamericana, 2000.

CERNA CABRERA, Jacinto Luis. El dialecto, la voz de los pueblos por

excelencia. Cajamarca, Perú, 2006.

CERRÓN PALOMINO, Rodolfo. El castellano andino. Aspectos sociolingüísticos, pedagógicos gramaticales. PUCP - GTZ, 2003.

ESCANDELL, M. Victoria. Introducción a la pragmática. Editorial Ariel, 2006.

ESCOBAR, Ana María. Contacto social y lingüístico. El español en contacto con el quechua en el Perú. PUCP, Fondo Editorial, 2000.

GIMENO MENÉNDEZ, Francisco. Dialectología y sociolingüística españolas. 1990.

GRANDA, Germán de. Estudios de lingüística andina. Lima, Perú, PUCP, Fondo Editorial, 2001.

GUERRA, Eliana. Reseña de "Diagnóstico sociolingüístico de Cumaribo, zona de contacto indígena-colono, Vichada" de Héctor Ramírez Cruz. Boletín de Lingüística, julio-diciembre, año/vol. XVIII, número 026. Universidad Central de Venezuela. Pp. 190200. 2006.

LÓPEZ MORALES, Humberto. Hacia el concepto de sociolingüística. En InterAmerican Review, 2, pp. 478-489, citado por De Granda, Germán: 2001. 1973.

QUESADA C., Félix. Quechua de Cajamarca. Lima, Perú, Editorial Mantaro, 2006.

PALACIOS ALCAINE, Azucena. Aspectos teóricos y metodológicos del contacto de lenguas: El sistema pronominal del español en áreas de contacto con lenguas amerindias. 2001.

PANTOJA ALCÁNTARA, Isabel del Rocío. Presencia del culli en el castellano regional de Santiago de Chuco- La Libertad. Tesis de maestría. UNMSM, 2000.

RUIZ DE MENDOZA IBÁÑEZ, Francisco José. Lingüística cognitiva: semántica, pragmática y construcciones. Universidad de la Rioja. 2001.

TORERO, Alfredo. Idiomas de los Andes. Lingüística e historia. Lima, Perú, IFEA, 2003.

WEINREICH, Uriel. Languages in Contact. United States, 1953. 